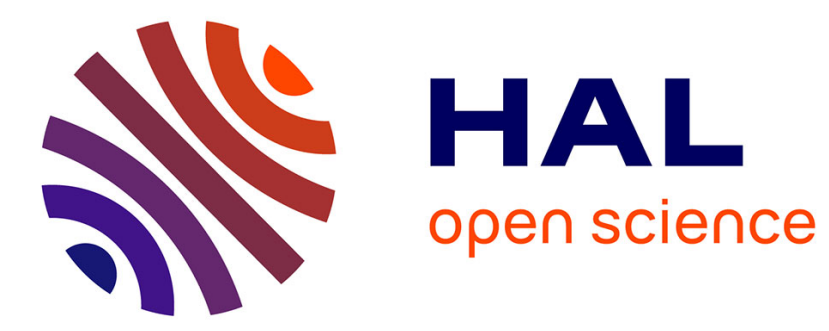

\title{
The panorama between mobile visual platforms is a sentimental bond
}

\author{
Gaby David
}

\section{To cite this version:}

Gaby David. The panorama between mobile visual platforms is a sentimental bond. Ubiquity: the Journal of pervasive Media, 2013, 2 (1), pp.146-163. 10.1386/ubiq.2.1.146_1 . hal-01911505

\section{HAL Id: hal-01911505 \\ https://hal.science/hal-01911505}

Submitted on 5 Feb 2020

HAL is a multi-disciplinary open access archive for the deposit and dissemination of scientific research documents, whether they are published or not. The documents may come from teaching and research institutions in France or abroad, or from public or private research centers.
L'archive ouverte pluridisciplinaire HAL, est destinée au dépôt et à la diffusion de documents scientifiques de niveau recherche, publiés ou non, émanant des établissements d'enseignement et de recherche français ou étrangers, des laboratoires publics ou privés. 


\section{GABY DAVID}

EHESS

\section{The panorama between mobile visual platforms is a sentimental bond}

\section{Abstract}

1. Technically, mobile images belong to the 'point-and-shoot' tradition. In this scheme, mobile visual applica-

2. tions have facilitated changes in both the aesthetic qualities of mobile images and their effortless sharing.

3. This mobile technology has developed hand-in-hand with its many different imaginable uses; for instance,

4. mobile modalities allowing families and friends to communicate enable the formation of strong audio-visual

5. bonds. This type of 'mobile visual habitus' is created through various sharing channels and can activate crea-

6. tivity, affection and social networks. Taking into account the intimacy involved in the use of mobile visual

7. apps, this article seeks to shed light on aspects of this everyday affective mobile visual usage. How does

8. mobile technology change our relationships with our own mobile visualities, our strong ties (i.e., bonds with

9. friends and family), and thus our own audio-visual private history construction and those of our loved ones?

10. As this question is overly broad, no exact answer or position can be determined. Nevertheless, through

\section{Keywords}

affection

bonds

intimacy

mobile photo

mobile video

sharing

visual apps 
1. The term 'mediascape' implies the recognition that landscapes can be defined as 'mediated places' through technologies in gecheral This general. This term stems from a video art exhibition sponsored by Deutsche Telekom at the Guggenheim Museum's Soho Galleries in New York in 1996; this exhibition explored the work of international artists dealing with changes in media technologies and the aesthetics of and the aesthetics of video art (Frohne et al. 1996). Within the academic discourse 'mediascape' is normally referenced in connection to Arjun Appadurai's discussion in Modernity at Large (1996: 35).

2. The original definition of the sociological term dispositif was introduced in Michel Foucault 'Le jeu de Michul Foucau t', in Michel Foucault', in 1977. See Chapter 11 in Michel Foucault and C. Gordon's 'The confession of the flesh:

What I'm trying to pick out with this term is, firstly, a thoroughly heterogenous ensemble consisting of micro-social networking examples, I intend to analyse how usage of mobile visual apps will continue to 1. change, influencing and enlarging possible methods of communication and engagement through and with 2 . private mobile images. These overarching practices will definitely continue to have an increasing impact in 3. connection with broader cultural and social changes.

\section{Introduction}

The most important audio-visual recording device developed in recent years has most likely been the 8 . mobile phone. Representing only the tip of the iceberg of what mobile phone culture is, changing and 9. influencing on the vernacular image proliferation and circulation, mobile phones and, by extension 10 mobile images, provide evidence of our need to carry with us representations of that which makes us 11 . who we are: our symbolic selves, our past and our connections to others, our symbolic selves. (I 12. would like to clarify that I have purposefully decided to use 'we' here, as I definitely include myself in 13 this population that relies on mobiles not only for communication but also for other daily activities as 14 well.) Many of the mediated affections, daily relationships and other interactions we engage in - 'our 15 favorite music, all our e-mails, today's newspaper, endless entertainment and of course a phone', as 16 an iPhone ad claimed in 2007 - are made tangible and easily accessible through this cultural object. 17.

Nowadays, the mobile phone can no longer be seen as a closed communication tool, but must 18 instead be analysed and comprehended as 'a portal that opens into many other spaces' (Goggin 19. 2012), a 'convergent hyper-medium' (Lee 2012), 'Universes of reference' (Chesher 2012: 98), or even 20. as a 'new media object' that serves (like all new media) to transform elements of culture and cultural 21. theory into an open source (Manovich 2001: 333). It has thus also been transformed into a tool for 22 constructing culture in a broader sense, not merely as an object of discourse or even an object used 23 . for discourse, but also through the mobile personal self-issues, reflexivity, social thought and new 24 awarenesses of the self (the $I$ ) and the collective (the we) that it unleashes and embodies (Caron and 25 Caronia 2007). This idea could also be understood in connection to the claims Marshall McLuhan 26 has expressed regarding the typewriter: namely, that it 'is a means of transcribing thought, not 27. expressing it' (McLuhan 1974, as cited in McLuhan et al. 1997: 289). Thus, the mobile is not an agent 28. in itself, but rather a cultural object that materializes many human expressions.

As with all cultural moments, sciences, technologies and habits, mobile images are the products 30. of their contexts, and are created and perceived together with all the discourses that intersect and 31 . inform the meanings attributed to them. It is within this fruitful image landscape that mobile films, 32.

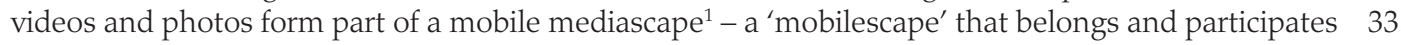
in a wider corpus of other dispositifs ${ }^{2}$ (Foucault 1994) and imagery, such as newspapers, magazines, 34 television, mobile film festivals, the Internet and social networks, as well as contributing to collective 35 . social identity constructions. 
1. When studying mobile visual habits such as taking photos or videos, questioning this habitus remains 2. a crucial aspect. To obtain a principled point of reference, I cite the concept of habitus as used by Marcel

3. Mauss, by Norbert Elias and by Pierre Bourdieu. In Mauss' classic paper 'Les Techniques du corps'

4. (1936), he brought up habitus as the acts of performance that define how a specific culture does certain

5. things (such as swimming, eating, running, climbing, etc.), and that uniquely identify different cultures 6. as such. In 1939, in The Civilizing Process, Elias interpreted the concept more in terms of etiquette, as the

7. self-restraining social manners and forms that are internalized and auto-imposed. In the 1970s and

8. 1980s, the concept was considered by the French sociologist Pierre Bourdieu, who expanded the defini-

9. tions of Mauss and Elias to include experiences as well, not only organic or mental dispositions, but also

10. the unconscious mental schemes of perceptions and actions that condition our behaviour.

11.

12.

Like Bourdieu, both Elias and Mauss used habitus as a way of discussing embodied subjectivity, 'practical knowledge' as Bourdieu calls it, but Bourdieu's distinctive contribution was to treat habitus as itself stratified across a society (as opposed to Elias and Mauss, who tended to think of habitus as stratified across different societies or epochs).

To relate these various interpretations to the field of mobile studies the ensemble of mobile phone

19. habits (in the sense expressed by Mauss and Elias) that people exhibit, including telephoning, play-

20. ing games, listening to music, texting and videotaping, could be generalized and more precisely

21. referred to as 'mobile habitus' (in a Bourdieusian sense). Even more specifically, within this mobile

22. habitus, I will refer to mobile imaging habits as behaviours that change and evolve hand-in-hand

23. with various technological changes and needs, but that still remain somehow characteristic of the

24. large majority of smartphone users. These usages (or this mobile visual habitus) are per se intrinsi-

25. cally fluid, flexible and spontaneous, continuously evolving with new mobile technologies, mobile

26. social networking (in which individuals converse and connect with one another through mobile

27. phones and/or tablets) and mobile apps - and obviously within and among the rest of the social

28. visualities. Thus, since mobile visual habitus is a concept in motion that changes at a constant and

29. almost imperceptible rate, it tends to often escape the attention of scholars.

30. Thus, it is important to observe the patterns of participation and changes exhibited in these habits,

31. whether in image creation, consumption or sharing processes. Mobile photography and mobile video

32. recording (or mobile visual habitus, collectively) have an impact not only on millions of people but also

33. on large sums of money. Forecasts and indicators in the telecommunications industries predict that this

34. growth will continue. There are many economic and technological reasons explaining the market pene-

35. tration of new mobile visual applications. However, emotional motives matter as well, although they are

36. often omitted or pushed into the background. Undertaking a self-reflexive approach, this article seeks to

discourses,

institutions,

architectural

forms, regulatory

decisions, laws,

administrative

measures,

measures,

scientific

philosophical,

moral and

philanthropic

propositions-in

short, the said

as much as the

unsaid. Such are

the elements of

the apparatus. The

apparatus itself

is the system

relations that can

be established

between these

elements. 
The panorama between mobile ...

describe and to reflect on some of the underlying affective motives explaining why mobile phones and 1 . apps are used as audio-visual recording and private sharing devices. Other types of sharing options 2 (such as blogging, online news, personal sites and torrents) are beyond the scope of this article.

\section{A tour of selected photo and video apps}

I subscribe to the opinion that the imagery of our generation will not be defined with a single filter - 7 . it will overlay multiple sounds and images, an over-stimulating mishmash of audio and visual' (Eler 8. 2012); I also believe that in the future, new generations will rely on audio-visual mnemonic materials 9. to an increasing extent. As proof of this trend, in April 2012 Facebook acquired Instagram for one 10 billion dollars, creating one of the most extensive mobile social-networking partnerships. However, 11. one could enquire: What was it that Facebook really bought, and more importantly, why? Instagram, 12. a mobile photo app and also a sharing platform, provides a service whereby still digital photos can 13 easily be modified (using set filter options) and then shared. Its strength is that it combines photog- 14 raphy, mobility and social networking. Users not only upload photos but also comment on them and 15 can even create new links. At the time of the company's acquisition, more than one billion mobile 16 photos had already been uploaded, with five million new photos being uploaded each day (Renardson 17 2012). However, 37 per cent of Instagram's users have never uploaded a single photo, and only 18 5 per cent of them have more than 50 pictures. By April 2012, Instagram had more than 30 million 19. registered users. Amazingly, the acquisition of the two-year-old company for US\$1 billion meant 20 that its value was higher than that of the New York Times, a 161-year-old company that (based on its April 2012 closing price on the New York Stock Exchange) was valued at US\$946 million.

Other theories and web rumours have speculated that the reason for such an expensive acquisition could be Prinstagram, a printing project that seeks to shift the trend back to printed photos, as nostalgia or perhaps a return to the roots of old-school photography. Through Prinstagram, physical prints in different options (ranging from mini-books and mini-prints to posters, photo books and calendars) are created directly from Instagram photos. There are currently additional printing options and objects (such as the Instagram Socialmatic camera) scheduled to be released as early as mid-2013, and products geared towards both online and physical sharing are also being proposed and launched in the market. Were these plans to make online photos more physical, more material and more profitable as prints the real reason that Facebook bought Instagram? Only time will tell. From a business perspec tive, this Facebook move is a win-win situation. On the one hand, Instagram achieves higher penetration thanks to the Facebook users who have hurried to download the app; on the other hand, by acquiring the free mobile photo-sharing application, Facebook continues to remain the largest online photo host. Additionally, many other 'grams' and 'Instas' have popped up as satellites, as if 'gram' and 'insta' were new verbs, prefixes or suffixes. For example, the new services being offered include 
1. Statigram (which provides statistics) and Followgram (which creates a 'vanity list' of followers); both of 2. these 'grams' are especially useful for branding, web analytics and customer engagement systems.

3. The underlying issues facing boutique photo-sharing apps can be identified as relating to how 4. one should present oneself in a competition for publicity. How can one be heard but still avoid the 5. pitfalls of marketing, narcissism and morality? How can one best succeed through these new 6. communication apps? For instance, since most campaigns are used to sell a product, how can a 7. collective project or an amusing but educational health campaign be publicized?

8. This last question was at issue in the case of Boobstagram a project founded by Julien GLT and 9. Lionel Pourtau, a sociologist. Boobstagram is a site where (female) users post and share photos, 10. mostly of their own breasts in bras or in skimpy clothing. In the 'About' page it is explained that the

11. site is not about showing breasts online, but rather about fighting against and raising awareness of

12. the risk of breast cancer. "We cannot all become doctors or surgeons. But we can all take part in

13. prevention, for ourselves, for our friends and family and for others', the French creators of the site

14. claim. How? 'By targeting young people, those who are most comfortable with new technologies

15. and most comfortable with unconventional messages'. Audacious and original, educational and

16. intended to promote preventative medicine, one can only hope their objectives will be fulfilled.

17. Thus, when we say that Facebook bought Instagram, we should also clarify the fact that Facebook

18. 'bought' many other apps and satellite start-up businesses that came attached to Instagram, includ-

19. ing unusual sites like Boobstagram. Being a sharing platform, Facebook acquired Instagram prima-

20. rily as a shutter and strong photographic component of a larger photographic dispositif.

21. Another important thing to bear in mind when considering an app - visual, audio-visual or any 22. other type - is the need to compare it to other similar and related options available on the market.

23. As of December 2012, the number of mobile photo applications was vast, and I will not seek to

24. perform an exhaustive comparison here. Nevertheless, there is one photo app I find stands out from

25. the rest: Pick. Originating from Japan, Pick is clearly a direct descendant of the well-known 'Purikura

26. photo aesthetic tradition', in which stamps, frames and words are added to images. ${ }^{3}$ As with

27. Instagram's eighteen filter options, in Pick, 22 filters can be applied to modify users' photos; in addi-

28. tion this free Japanese app offers 111 photo frames and many different amusing stamps (as counted

29. in December 2012 and verified in January 2013). On top of all that, drawing and writing on the

30. mobile photos is possible as well. By offering these modes of appropriation, Pick allows users to

31. modify their photos, enabling them to weave feelings from, within and towards the image. In this

32. way, the mobile photo can more easily be used as a message in itself and not merely as an illustra-

33. tion of a textual message. With an app like Pick, there is no longer the need to transform an SMS

34. into an MMS (in the sense of adding an image to a text message or a caption to an image); here, the

35. image itself can be turned into the message, and the text (should there be any) can be written on the

36. photo. As a result, the two aspects operate as one inseparable sign.
3. For more on Purikura and its social functions, see Richard Chalfen and Mai Murui (2004). 
The panorama between mobile ..

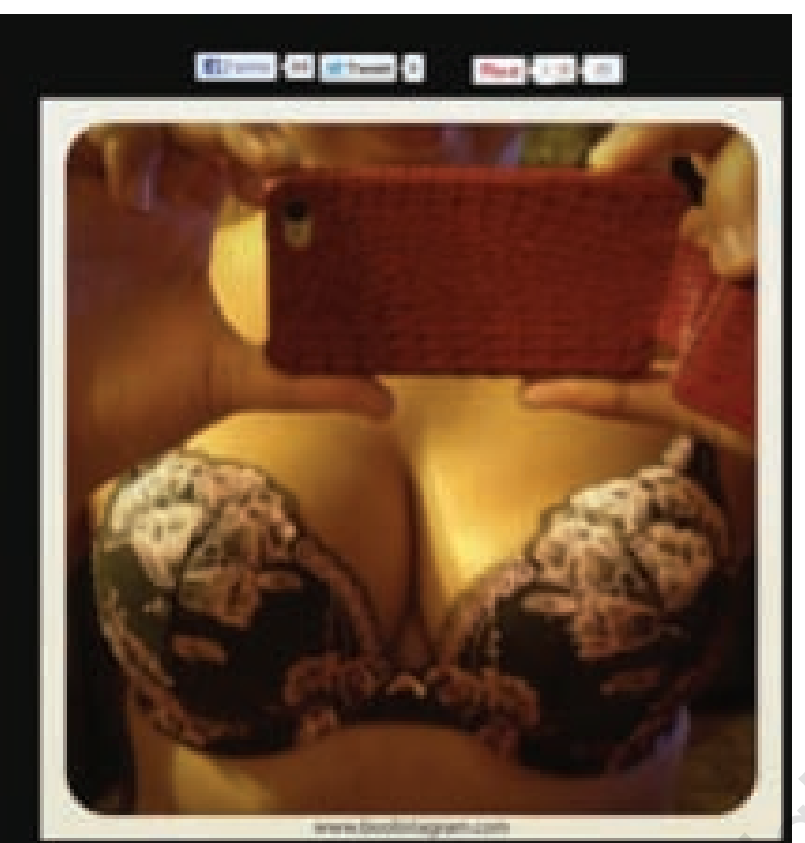

Figure 1: Screenshot taken from Boobstagram.

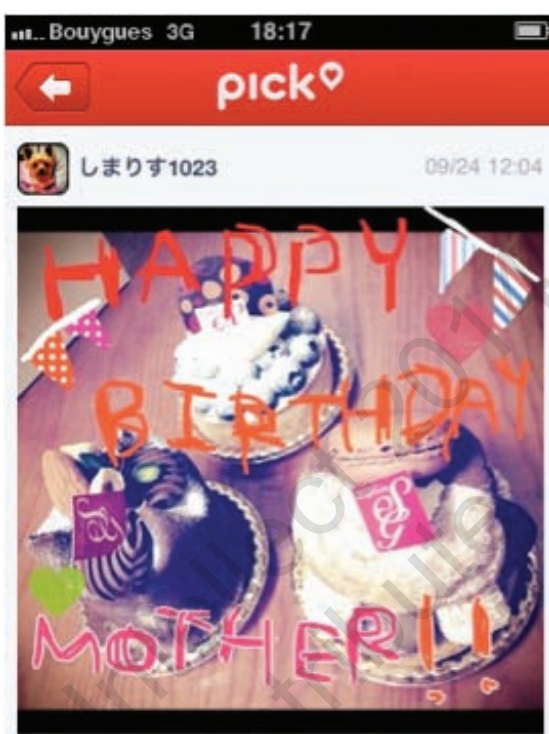

昨日はお母さんの除生日!ケーキをブレぜン ただきまーすルマ゙・に トっ(*^^*)うー我偍できないのて、おお先にい

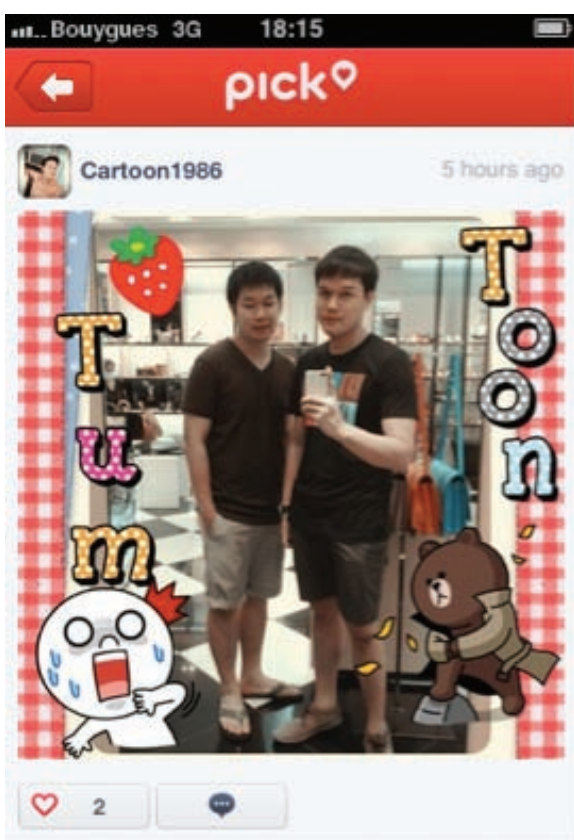

Figure 2: Screenshots taken from two different Pick users.

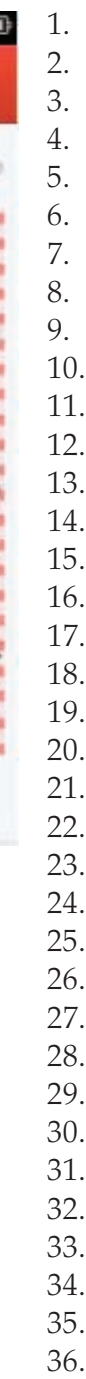


As of December 2012, due to cultural differences, Pick had not really penetrated the interna2. tional market the way Instagram has. What works well in some countries might not be readily 3. adopted in the rest of the world. However, by February 2013, the company's home page had been 4. transformed, and signs point to Pick's expansion into a more international market. If your friends

5. are already using Instagram, however, you would clearly be more prone to be active on that site, 6. even though Pick might technically offer more functionality (as of February 2013). As with the

7. consumption of any cultural commodity, it is the possibility of socialization that drives our participa8. tory decisions

9. In Everett M. Rogers' description of the processes of diffusion, adaptation and appropriation of 10. innovations for social change, one of his first remarks is that the quality that makes any innovation

11. spread successfully is its improvement on the idea or the innovation that it supersedes - improve-

12. ments that can be economic or based on social prestige, convenience or satisfaction (Rogers 1983).

13. Furthermore, most of the time, new technologies mimic and relate to previously known forms. This

14. factor of connecting the old with the new facilitates the acceptance of new ideas and mitigates the

15. impact of the new innovation (Bolter and Grusin 1999). With respect to mobile innovations and

16. mobile apps, some are more entrenched in common usage than others. In marketing, such apps are

17. referred to as 'killer apps'. These are apps that seem to be so essential or desirable that they define

18. the core value of a larger technology. In the case of mobile applications, the most significant exam-

19. ple of a killer app is the code that allows the transmission of SMS messages. Photo-sharing apps are

20. not yet killer apps, but the use of the embedded camera, combined with apps that enable quick

21. photo editing and instant-messaging apps, might soon extend their influence and utilization. In the

22. next mobile generation, it is expected that the killer applications will be those that allow P2P file

23. sharing, instant messaging and e-commerce.

24. In 2012, the sharing of mobile photos is generally comfortable, easy and quick. It should be 25. noted that mobile visual exchange does not always proceed without obstacles. Sometimes the person 26. receiving the image does not have a handset capable of reading images properly, and then the visual

27. dialogue is quickly cut off. However, when it is possible, photo sharing can be accomplished very 28. rapidly, with only a couple of finger taps and clicks. There is no need for cables, keys, Bluetooth

29. downloads or any intermediary software applications; sometimes not even a password is required.

30. The ease of acquiring and using the apps is also important to take into account, as it can have a great

31. impact. For example, in Instagram, unless you sign up for an account, it is impossible to see images

32. from the site on your mobile: a heart shape icon appears on top of the images, stopping you from

33. visualizing them properly and compelling you to join the site. In addition, as most sites do now,

34. Instagram prompts you to register by offering the option to log in through either your Facebook or

35. Twitter account. This blends and integrates the apps into the larger ecology of social networks,

36. which are above all the display and exhibition spaces of private iconic production. The possibility to 
change, alter and opacify the photo using the range of different filters and effects has also influenced 1 . its success (Palmer 2012; Gunthert 2012).

If we empirically compare the growth in the use of mobile photos to the introduction of mobile 3 . video applications and their use, it appears that video has grown more slowly than the photo apps 4 . but in quite a similar way. For instance, one example of a mobile-based live video-sharing website is 5 . Qik. Launched in its alpha version in December 2007 and in public beta in July 2008, Qik was the 6 . first mobile video service to support Facebook Connect (in April 2009). In January 2011, Skype 7. bought Qik for the sum of 100 million dollars.

I have been using Qik and following its growth since its launch. However, it was not until late 9. 2011 that the videos I had posted in the past were easily shareable with my other social networks. 10 Until that point, they were latent images waiting to be shared and viewed. Currently, the videos on 11 . Qik can easily be posted to and shared via Facebook, Twitter, YouTube and many other social 12 network sites (see Figure 3 below). This cross-media business deal (or transmedia, using Henry 13 Jenkins' (2006) definition) was also important because it continued to connect this mobile video 14 . platform to well-known Internet social-networking and communication channels such as Facebook, Twitter and YouTube.

As seen in the photo app boom (2010-2012), and because visual apps are under constant development, it is likely that in the near future a 'mobile video turn' might soon enable mobile videos to achieve more popular impact, fame and global penetration. However, as Richard MacManus, the founder and editor-in-chief of ReadWriteWeb claims (2012), 'the video is only half of the equation. The other half is socializing it'. The will and need to share must be there and somehow be implemented. Collective social mobile video experiences are being created, with innovation emerging from artistic projects and from more militant collaborative projects involving multiple cameras. This transformation from the iPhone to the 'wePhone' and the 'we-cam' will offer new possibilities in filming and recording participatory phenomena (Miles 2012).

Among the mobile video-sharing platforms launched in 2012, three are especially worthy of mention: Socialcam, Viddy and Klip. In 2013, while I am writing this article, Vine and other shor six-second-video-sharing platforms are seeing light. But, when faced with the choice of which video app to adopt, with plenty to choose from, many of the factors contributing to the decision boil down to where your friends and family are. I was already using Qik, and because none of my contacts were active in any of these mobile video platforms, I did not really have the need or urge to participate in any of them. I do take videos sometimes, but I share them only with my family scattered throughout the world. Every Friday, we exchange photos, videos and messages through an app called WhatsApp.

For the photos I share in WhatsApp, I use images from my iPhone gallery. Sometimes I use other photo-editing apps to modify an image before sending it through WhatsApp. For videos, 
Gaby David

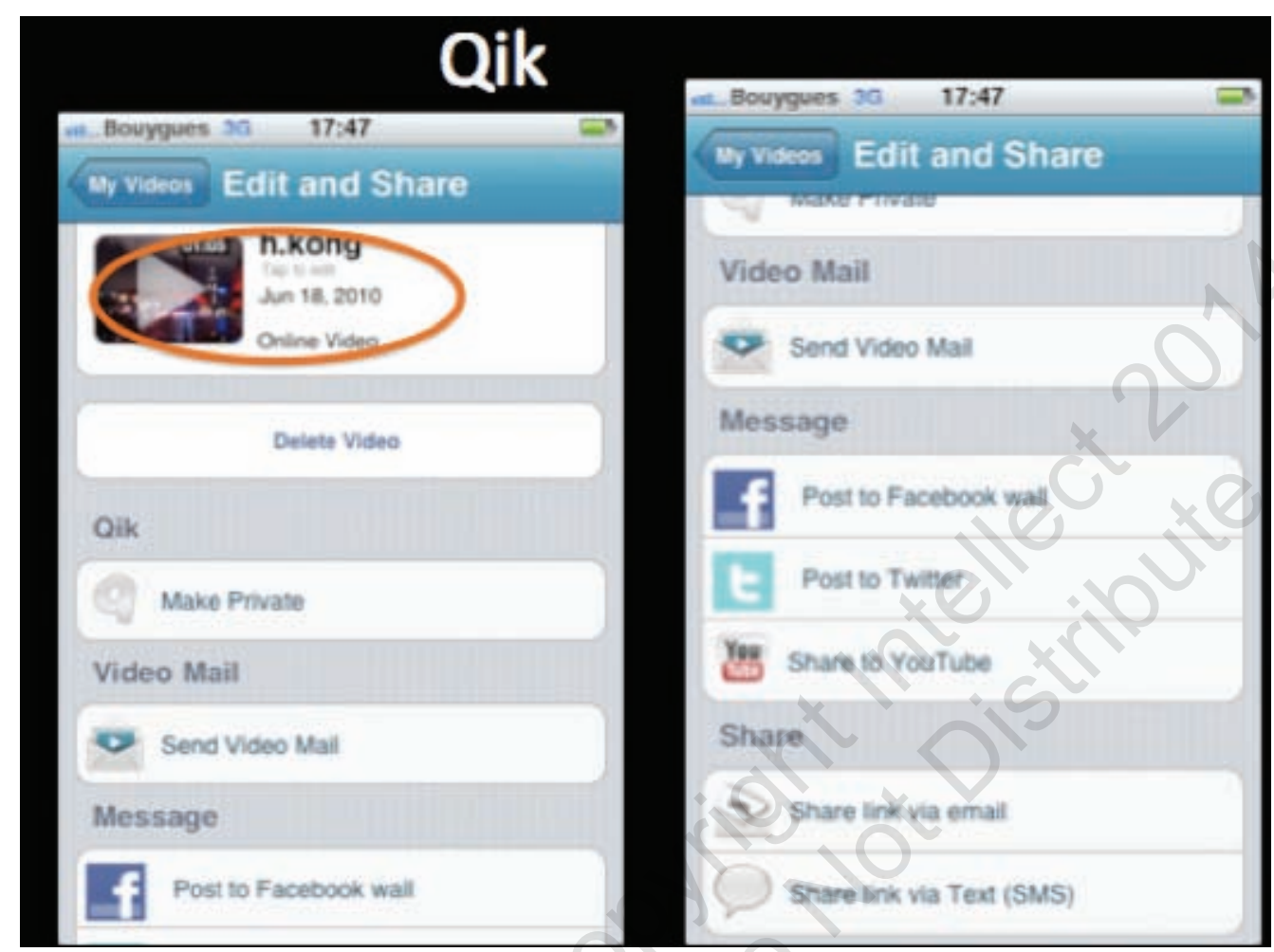

$\oplus$

Figure 3: Screenshot of Qik's mobile sharing possibilities, 2012. 
The panorama between mobile ...

I use the embedded video-camera function on my mobile phone, without editing. The difference in 1 . the mobile visual habitus between the editing of mobile photos and the lack of editing of mobile 2 . videos is based on the fact that mobile video-sharing apps allow (as of 2012) only short videos to be 3 . sent. Given this limitation on file size, the length of the mobile videos we take and share through 4 . WhatsApp must be less than about a minute long; therefore, the videos do not require much editing. 5 . WhatsApp is a cross-platform mobile messaging application that costs 99 cents to download; after 6 . downloading, all exchanged messages are free. In relationships in which the 'absence-presence' 7. (Gergen 2002) factor matters a great deal, the ease of use for image and audio-visual sharing is key. 8 . Furthermore, it seems that the most important thing is joining the platform, app or means of sharing 9 . that your loved ones use. Family app packages and group offers should therefore be taken into 10. account.

$$
\text { ( }
$$

Moreover, in my own decision on what to use, the possibility of having a closed, private imageexchange group (photos and videos together in one app) was crucial as well. I have created two groups: one with my immediate family of four, and a larger one with seven of my relatives. In my opinion (as of 2012), WhatsApp is one of the best apps and instant messaging platforms for sharing messages, pictures, audio notes and video messages with a private group of people, allowing all participants to be in the loop. Being able to create small closed groups to comment on, discuss and share pictures and videos, while trying to safeguard privacy, addresses the need for a private place to re-affirm strong personal ties.

Let us review the process a mobile photo might undergo from its production to its posting within a private circle. First, the photo can be shot either with the camera app that comes embedded in the mobile device or with any other photo app the user might have previously downloaded. Second, photo filters can be applied and the image can be aesthetically altered, changed and edited. It can then be sent either through private MMS or private e-mail or posted to Facebook, Twitter or any other social-networking site. It could also be shared in a more private sphere through WhatsApp or any other similar service; for instance, Kik, another instant-messaging app for mobile devices. But, between these two mobile instant-messaging apps are two main differences. Kik is free and WhatsApp is not. In addition, Kik's messenger uses a username (pseudonym) instead of a phone number, allowing more privacy than other forms of text messaging. In all of these sharing steps, the images might be commented on or modified again as well. With regard to mobile videos, the shar ing chain is somewhat similar, with the primary difference that mobile video platforms also have a live streaming option. This enables users to film for longer than one minute and to share the mobile video by simply sharing the live-stream link.

What makes these apps so successful? Is it merely a trend? Is it the fact that they are free or offer a user-friendly service? Is it their marketing or advertising campaigns? Or does their popularity spread through word of mouth? Probably all of the above factors play a role. To answer the first of 


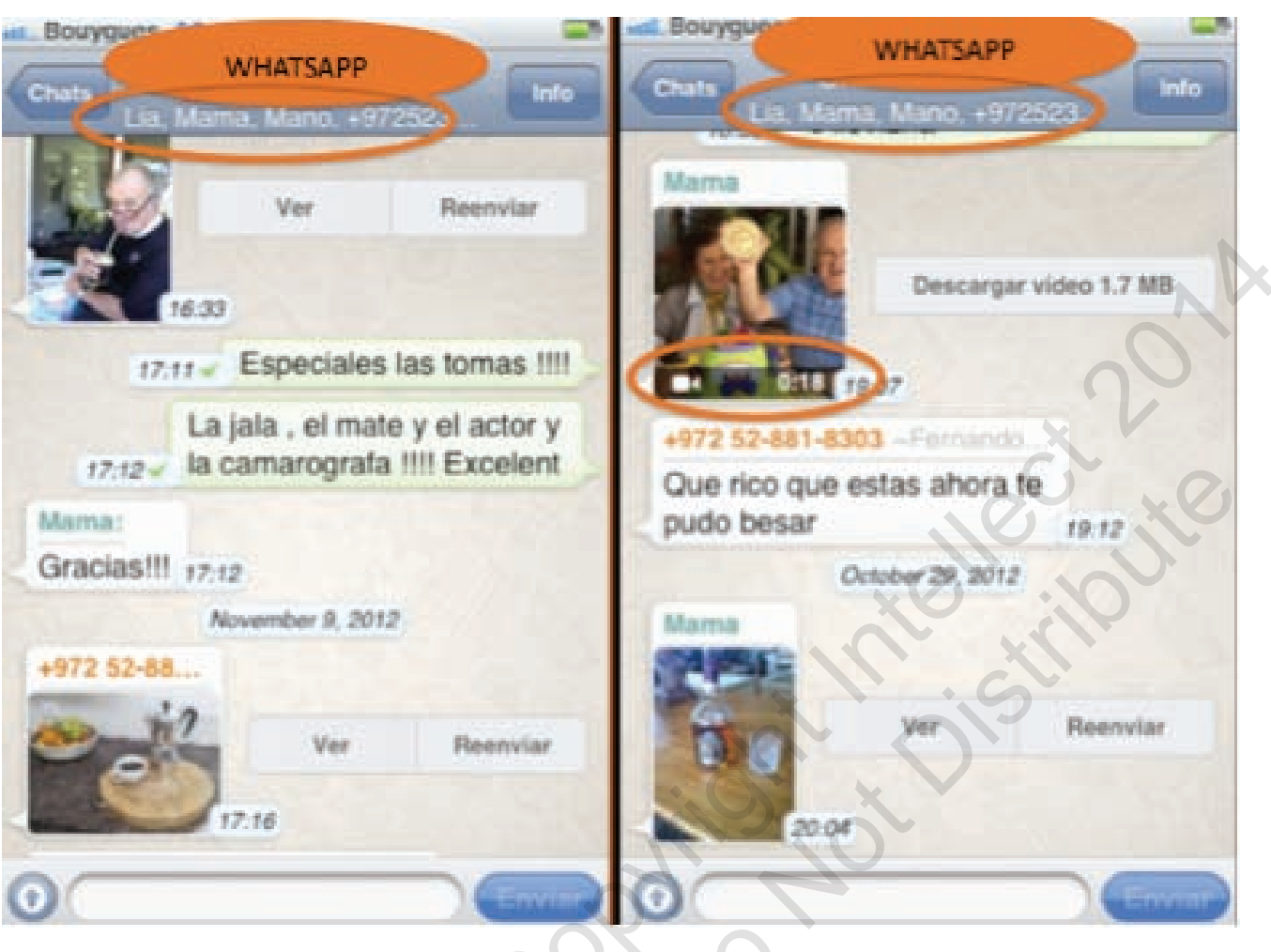

Figure 4: Screenshot of WhatsApp from my personal mobile phone.

28.

29.

30.

31.

32.

33.

34.

35.

36. 
The panorama between mobile ...

these complex questions, it might help to quote Don Draper, the advertising executive and main 1 . character of the American television series, Mad Men (Weiner, 2007). In the last episode of the first 2. season, called The Wheel, Don gives a memorable presentation as he pitches 'The Carousel for 3 . Kodak' to his clients, representatives from the Kodak film company:

Well, technology is a glittering lure. But there's the rare occasion when the public can be engaged on a level beyond flash, if they have a sentimental bond with the product.

Creating this affective link or 'emotional capital' (Jenkins 2006: 68-69) is an important business 10. strategy and represents one of the goals of most advertisements. However, this capital must be acti- 11. vated. Consequently, in a touching scene, Don continues his presentation by relating the Carousel 12 . product to the importance of nostalgia. His words resonate with the feelings we project onto any 13 beloved object, anything that has emotional power:

[...] a deeper bond with the product: nostalgia. It's delicate ... but potent. [...] in Greek, 'nostalgia' literally means 'the pain from an old wound'. It's a twinge in your heart, far more powerful than memory alone. This device isn't a spaceship. It's a time machine. It goes backwards, forwards. It takes us to a place where we ache to go again. It's not called the Wheel. It's called a Carousel. It lets us travel the way a child travels. Around and around, and back home again... to a place where we know we are loved.

Apart from the ritual of gathering people together for a special slide screening, what else differenti- 24 ates the Carousel and Instagram? One of the main differences between the Kodak Carousel's wheel 25. and Instagram's image feed is that the analog photography reel can be understood more in terms of 26 nostalgia about the past, whereas the moment in time to which mobile photographs transport the 27 . viewer is controversial. One could theorize that Instagram's filters link us to moments in the past 28. (Bartholeyns 2012), or they could be interpreted using a 'tomorrow's photography' approach 29. (Gunthert 2012). I follow the latter interpretation, adding that it is precisely Instagram's infinite reel 30. dispositif that projects its users into a near future to come, at the same time demonstrating that the 31 . present is the most ephemeral moment in time.

Instagram's carousel or photo feed neither stops nor repeats its combinations. It is as though the 33 . present had one foot in the future and another in the past. In this yesterday/now/almost-future, we 34 expect the next photo to continue the feed. Because Instagram's feed is an infinite collection of 35 . mobile photos that rolls out as soon as the photos are shared - and, most importantly, because the 36 
1. reel never stops - there is no moment when the lights turn on and we 'come back' to the room and

2. reality around us. Our mobile images are seen on the go, are carried with us and can be invoked and

3. viewed whenever desired. They are not a 24-slide carousel that is put away and only seen once in a

4. blue moon. These sequences of synchronic and separate images depict a multitude of events gath-

5. ered in one app, in one handset and one specific moment in time. It should also be noted that it is 6. very rare that two people will have exactly the same contacts, and thus no two handsets will have

7. the same Instagram photo reel; as a result, unlike the Kodak Carousel, the experience is perceived 8. more individually than collectively.

9. Thanks to popular image production, the quantity of mobile photos is greater than it has ever 10. been. Moreover, as mobile tools facilitate the recording and display of everyday life, mobile images

11. have become another commodity to be both produced and consumed at increasing rates. It seems as

12. though the more often and the faster we create these mobile images, the faster we go through them;

13. this mobile image production and consumption underscores the ephemerality of the moments of

14. our lives and our drive to register them. Mobile photography is developing into a commodity model,

15. and what was previously a marginal behaviour is becoming a mainstream practice.

\section{Conclusion: Mobiles as hybrid visual memo pads}

19. In an article entitled 'A note upon the "Mystic Writing Pad"', Sigmund Freud (1925) discusses

20. different ways of improving mnemonic functions; that is, skills of memorizing and remembering.

21. The first method discussed is note-taking on a writing surface that will preserve intact any note

22. made on it for an indefinite length of time (e.g. a sheet of paper). This procedure has a certain

23. advantage, as it provides a 'permanent-trace', but it also has two distinct disadvantages. The first

24. drawback is that once the writing surface is full, it cannot be written on again; the second is that the

25. personal interest towards it might disappear and the trace might therefore lose its value. A parallel

26. could be drawn with analog photo cameras: once the photo film has been used up, there is no

27. longer any possibility to record information. The photos will be printed and tangible, but will even-

28. tually lose relevancy. The second mnemonic procedure discussed is the use of surfaces that can be

29. written on more than once and are therefore more receptive. These could include a slate, a piece of

30. clay or a whiteboard, objects that are erasable and allow notes to be inscribed again and again. The

31. disadvantage here is that no permanent trace of the information will remain. An analogy can be

32. made between such objects and digital cameras and their digital images. Since there is no need for

33. film, once the memory card is full, photos can be erased and recording can continue indefinitely. In

34. the last part of his article, Freud continues his analysis by referring to a 'Mystic Writing Pad', a

35. hybrid between the two mnemonic procedures. On such a pad, traces could either be erased or read

36. 
The panorama between mobile ...

4. This key question stems from Maurizio Ferraris' article 'Where are you? Mobile ontology' (2006) under the proper light. Freud compares the appearance - disappearance of celluloid and its wax- 1 . paper cover 'with the flickering-up and passing-away of consciousness in the process of perception' 2 . (1925: 211), in a comparison between our mental apparatus and its perceptive functions. Could we 3 . relate the 'Mystic Writing Pad' to taking photos with one's mobile phone? ${ }^{4}$ Often, these visual 4. mobile apps function as mystic pads, as places where one can reference old images not explicitly 5 . saved by the user, but rather in the site's cloud storage. (Cloud storage services allow the virtual 6 . storage of data, videos, images and music and remote online backup.) The mobile device functions 7 . in this hybrid fashion: mobile images can be either stored or erased. Should the handset run out of 8 . memory space, requiring the user to erase mobile images, logging into any of these sites would 9. enable the user to find the lost images again. At the moment (2012), the number of mobile photos 10 and videos one can upload to these sites is infinite and usage is free of charge. However, nothing 11. ensures that a 'pro' subscription will not be proposed in the future, as has already happened with 12 . the well-known image-and-video-hosting site Flickr. Flickr's Pro account proposes for an annual 13 fee of \$24.95 unlimited storage, ad-free browsing and access to account statistics, among other 14 benefits. If these smaller sites are not acquired by one of the Internet giants, it might be the case 15 . that more branding or the increased use of advertisements will be the economic model for the 16 . survival of these apps.

With market penetration of smartphones already changing the world - from how we shop and 18. how we keep ourselves entertained to how we navigate the world - contact with personal mobile 19. images will occur even more on an increasingly frequent basis. Whether through mobile photos or 20 mobile videos, the adoption of mobile visual apps is connected to the increase in the global and 21 . mobile way of life that enables more mobile image creation and circulation. As they are easy to use, 22. mobile visual apps are used frequently and by large numbers of people. The possibility of sublimat- 23 ing these mobile images with multiple filters and esthetical changes and the almost effortless shar- 24. ing of these mediated moments and experiences, provides evidence of how important and dear these artefacts are to us.

However, the focus should be placed on interpersonal links rather than the images as independ- 27 ent entities. For example, when one has a robust relationship or a strong tie with the person who 28 . posts a photo, regardless of what exactly the image itself portrays (or whether or not it is a beautiful 29. photo), a conversation is usually triggered, and thus the affective link is involved and somehow 30. nurtured. When weaker ties are involved, this process is less frequent, but might also take place. By 31. viewing photos, in only a few minutes many different atmospheres and aesthetic styles from diverse 32. people and therefore locations and entire universes can be visited, 'liked' and commented on. 33. Looking at, zipping through, commenting on, reading comments and 'liking' the mobile images of 34 far-away friends, relatives or even various weak contacts can be a daily reward we offer to ourselves. 
1. The basis of mobile social-networking sites is that they activate and heavily rely on sentimental

2. bonds, affections, family ties and the creation and maintenance of friendships.

To create a more affective, bonded and collective 'countervisuality or right to look' (in Mirzoeff's words (2011)), it is important to continue investigating and analysing this participatory sharing of private visual mobile experiences, not only in weak but also in strong ties. These downloadable memories and mobile image sites alter the relationships we have with our friends and the strong ties of family, and also play a significant role in how we relate to our own mobile images. Visual mobile social-networking sites are facilitating changes in the ways we create and speak about mobile images.

9. When these sites are used on a regular basis, the visual skills activated can influence the perception

10. of the audio-visual private history construction of our own families and friends, and consequently

11. have an effect on the wider mobile culture.

All screenshots were taken by the author between November 2012 and February 2013.

\section{References}

Appadurai, Arjun (1996), Modernity at Large: Cultural Dimensions of Globalization, Minneapolis, MN: University of Minnesota Press.

Bartholeyns, Gil (2012), 'L'iPhonographie: la machine à fabriquer le temps, Culture Visuelle', Culture Visuelle, Média social d'enseignement et de recherché, 23 April, n.p., http://culturevisuelle.org/ blog/10514. Accessed 5 December 2012.

21. Bolter, J. David and Grusin, Richard (1999), Remediation: Understanding New Media, Cambridge, MA: MIT Press.

3. Bourdieu, Pierre, Boltanski, Luc, Castel, Robert, Chamboredon, Jean-Claude and Schnapper, Dominique (1990), Photography: A Middle-brow Art (trans. Shaun Whiteside), Stanford, CA: Stanford University Press.

Caron, André H. and Caronia, Letizia (2007), Moving Cultures: Mobile Communication in Everyday Life, Montréal: McGill-Queen's University Press.

Chalfen, Richard and Murui, Mai (2004), 'Print club photography in Japan: Framing social relationships, in Elizabeth Edwards and Janice Hart (eds), Photographs Objects Histories: On the Materiality of Images, London: Routledge, pp. 166-85.

Chesher, Chris (2012), 'Between image and information: The iPhone camera in the history of photography', in Larissa Hjorth, Jean Burgess and Ingrid Richardson (eds), Studying Mobile Media: Cultural Technologies, Mobile Communication, and the iPhone, New York, NY: Routledge, pp. 98-117. 
The panorama between mobile ...

Eler, Alicia (2012), 'A look into 3 social video apps: Socialcam, Viddy \& Klip', ReadWrite-Web Apps, 1. Web Technology Trends, Social Networking and Social Media, n.p., 2 May, http://readwrite. 2. com/2012/05/02/a-look-into-3-social-video-apps-socialcam-viddy-klip. Accessed 4 December 2012.3.

Ferraris, M. (2006), 'Where are you? Mobile ontology', in K. Nyíri (ed.), Mobile Understanding: The 4. Epistemology of Ubiquitous Communication, Vienna: Passagen Verlag, pp. 41-53.

Foucault, Michel (1994), Le jeu de Michel Foucault: Dits et écrits, vol. 2, Paris: Gallimard.

Foucault, Michel and Gordon, C. (1980), Power/Knowledge: Selected Interviews and Other Writings, 8. 1972-1977 (trans. C. Gordon L. Marshal J. Mepham and K. Sober), New York: Pantheon Books. 9.

Frohne, Ursula, Seifer, Oliver and Blunck, Annika (1996), 'Full text of “Mediascape"', Internet 10 Archive: Digital Library of Free Books, Movies, Music and Wayback Machine, n.p., 14 June, http:// 11. archive.org/stream/mediascape00klot/mediascape00klot_djvu.txt. Accessed 15 March 2013.

Freud, Sigmund (1925), 'A note upon the "Mystic Writing Pad"', home.uchicago.edu/ awinter/ 13 mystic.pdf. Accessed 15 March 2013.

Gergen, Kenneth J. (2002), 'The challenge of absent presence', in Katz, J. E., \& Aakhus, M. A. (eds) Perpetual Contact Mobile Communication, Private Talk, Public Performance, Cambridge: Cambridge University Press, pp. 227-40.

Goggin, Gerard (2012), 'The iPhone and communication', in Larissa Hjorth, Jean Burgess and Ingrid Richardson (eds), Studying Mobile Media: Cultural Technologies, Mobile Communication, and the iPhone, New York, NY: Routledge, pp. 11-27.

Gunthert, André (2012), 'Instagram, photo d'hier ou de demain?', L'Atelier des icônes, Culture Visuelle, Média social d'enseignement et de recherché, 11 April, n.p., http://culturevisuelle.org/ icones/2350. Accessed 4 December 2012.

Jenkins, Henry (2006), Convergence Culture: Where Old and New Media Collide, New York: New York University Press.

Lee, Dong-Hoo (2012), '“In Bed with the iPhone”: The iPhone and hypersociality in Korea', in Larissa Hjorth, Jean Burgess and Ingrid Richardson (eds), Studying Mobile Media: Cultural Technologies, Mobile Communication, and the iPhone, New York, NY: Routledge, pp. 63-81.

MacManus, Richard (2012), 'ReadWrite - why “Instagram For Video" apps will go big', ReadWrite - Web Apps, Web Technology Trends, Social Networking and Social Media, 3 May, n.p., http:// readwrite.com/2012/05/03/why-instagram-for-video-apps-will-go-big. Accessed 4 December 2012

Manovich, Lev (2001), The Language of New Media, Cambridge, MA: MIT Press. 
Gaby David

1. Mauss, Marcel (1936), 'Les techniques du corps', Journal de Psychologie, XXXII, 15 March-15 April, pp. 3-4. (Communication presented at the Société de Psychologie, 17 May 1934.)

McLuhan, Marshall, McLuhan, Eric and Zingrone, Frank (1997), Essential McLuhan, London: Routledge.

Miles, Simon (2012), 'Co-authorship and interactivity in multi-cam mobile filmmaking', in MINA, Mobile Innovation Network Aotearoa, 2nd Mobile Creativity \& Mobile Innovation Symposium, Mobile 2.0: Participation and Interactivity, Massey University, Wellington, New Zealand, 24-25 November.

Mirzoeff, Nicholas (2011), The Right to Look: A Counterhistory of Visuality, Durham, NC: Duke University Press.

Palmer, Daniel (2012), 'iPhone photography: Mediating visions of social space', in Larissa Hjorth, Jean Burgess and Ingrid Richardson (eds), Studying Mobile Media: Cultural Technologies, Mobile Communication, and the iPhone, New York, NY: Routledge, pp. 85-97.

Renardson, Adam (2012), 'Instagram facts and figures, what has Facebook bought?', New Media, Ireland's technology news service Siliconrepublic.com, 10 April, n.p., http://www.siliconrepublic. com/new-media/item/26617-instagram-facts-and-figures/. Accessed 9 June 2012.

Rogers, Everett M. (1983), Diffusion of Innovations, 3rd ed., New York: Free Press.

Sterne, Jonathan (2003), 'Bourdieu, technique and technology', Cultural Studies, 17: 3-4, May-July, pp. 367-89.

YouTube (2007), 'Apple iPhone Ad: Amazing', 9 September, n.p., http://www.YouTube.com/ watch?v=ZxtyxCAxGNE. Accessed 13 September 2012.

Weiner, Matthew. (18 Dec. 2007), Mad Men, The Wheel, Season 1, Episode 13, (n.d.), 'Mad Men: The Carousel', n.p., http://www.youtube.com/watch?v=R2bLNkCqpuY. Accessed 8 December 2012.

\section{Suggested citation}

David, G., (2013), 'The panorama between mobile visual platforms is a sentimental bond', Ubiquity: The Journal of Pervasive Media 2: 1, pp. 146-163, doi: 10.1386/ubiq.2.1.146_1

\section{Contributor details}

34. Gaby David, Uruguayan, living in Paris, is currently completing a Ph.D. in Visual Cultural Studies, at 35. the Laboratoire d'Histoire Visuelle Contemporaine (Lhivic), from the 'Arts et images' department of the 


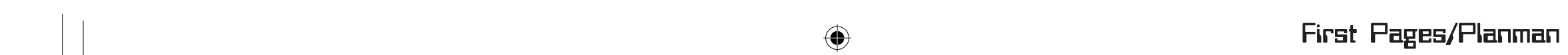

The panorama between mobile ...

EHESS École des Hautes Etudes en Sciences Sociales. At the Lhivic she has co-directed the 1. methodological seminar for Ph.D. candidates. Masters degree in Fine Arts and TEFL's (Teacher of 2. English as a Foreign Language) degree she has taught English, Spanish and Visual Culture in places 3. such as the Parisian Parsons School of Arts and Design, Sciences Po Rennes and enterprise frames. 4. With a strong dance-theatre background, her portfolio also includes numerous art exhibitions and 5 . performances. She has also participated in a project sponsored by the French National Research 6. Association that studied the state of the arts in the digital era. In the academic field she has spoken 7. at numerous international conferences (Engagement and Exposure-Budapest, 2nd Digital Cultures- 8. Manchester, HITI Sorbonne-Paris, Chinese University of Hong Kong, among others) and partici- 9. pated in several seminars, always centring her research on the visual mobile mediascape. At the 10 . Lhivic and since its creation in 2009, she is part of the editorial Advisory Board of Culture Visuelle, 11. the first French social media teaching and research platform, where she holds her own blog, 12. Corazonada. Her field of research focuses in the Mobile and Media Studies and her thesis project 13. concentrates on the Social Uses of Mobile Images.

Contact: 4 Rue Championnet, 75018 - Paris, France.

E-mail: david@lhivic.org 